\title{
Setbacks in the process of assimilation of problematic experiences in two cases of
} Emotion-Focused Therapy for depression

\author{
Inês Mendes ${ }^{\mathrm{a}}$, Catarina Rosa ${ }^{\mathrm{c}}$, William B. Stiles ${ }^{\mathrm{f}}$, Isabel Caro Gabalda ${ }^{\mathrm{e}}$, Pedro \\ Gomes $^{\mathrm{b}}$, Isabel Basto ${ }^{\mathrm{d}}$, Isabel Caro Gabalda ${ }^{\mathrm{e}}, \&$ João Salgado ${ }^{\mathrm{b}}$
}

\begin{abstract}
${ }^{a}$ CIPsi - Psychology Research Center, Psychotherapy and Psychopathology Research Unit, School of Psychology, University of Minho, Braga, Portugal \& ISMAI University Institute of Maia, Maia, Portugal

${ }^{\mathrm{b}}$ ISMAI - University Institute of Maia, Maia, Portugal and Center of Psychology at University of Porto, Porto, Portugal

${ }^{c}$ University of Aveiro, Aveiro, Portugal; Ibili - Institute for Biomedical Imaging and Life Sciences, University of Coimbra, Coimbra, Portugal.

${ }^{\mathrm{d}}$ CINNEIC, Faculty of Psychology and Educational Sciences, University of Coimbra, Coimbra, Portugal

${ }^{\mathrm{e}}$ Department of Personality, Assessment and Psychological Treatments, University of Valencia, Valencia, Spain

${ }^{\mathrm{f}}$ Miami University, Ohio, USA \& Appalachian State University, North Carolina, USA
\end{abstract}

Correspondence details: Correspondence concerning this article should be addressed to Inês Mendes, School of Psychology, University of Minho, 4710 Braga, Portugal. Email: inesmendes@ psi.uminho.pt

\section{Funding}

This article was supported by the Portuguese Foundation for Science and Technology (FCT) under the grant PTDC/PSI-PCL/103432/2008 (Decentering and change in psychotherapy, 2010-2013) and under the Postdoctoral research grants SFRH/BPD/98196/2013 and SFRH/BPD/80671/2011. 


\begin{abstract}
Objective: Research on the assimilation model has suggested that psychological change takes place in a sequence of stages punctuated by setbacks, that is, by transient reversals in the developmental course. This study analyzed such setbacks in one good-outcome case and one poor-outcome case of Emotion-Focused Therapy for depression.
\end{abstract}

Method: Intensive analyses of five transcribed sessions from each case identified 26 setbacks in the good-outcome case and 27 in the poor-outcome case. The reason for each setback was classified into one of four categories: balance strategy, exceeding the therapeutic zone of proximal development either induced by the therapist (ZPDT) or induced by the client (ZPD-C), or spontaneous switches.

Results: In the good outcome case the most frequent reasons for setbacks were balance strategy and spontaneous switches, whereas in the poor outcome case the most frequent reason for setbacks was ZPD-T.

Conclusions: As in previously studied therapies, setbacks in Emotion-focused therapy, usually represent productive work on relatively less advanced strands of the client's major problems. Results point to the importance of the therapist attending to the limits of the client's therapeutic ZPD.

Keywords: Assimilation model; APES; setbacks in psychotherapy; process research; emotion-focused therapy 


\section{Setbacks in the process of assimilation of problematic experiences in two cases of Emotion-Focused Therapy for depression}

A setback is a seeming reversal in the process of therapeutic change, a step backwards that may represent a retreat or may represent a process of consolidating gains, examining varied aspects of a problem to foster the integration of conflicting parts of the self that are causing distress (Caro Gabalda \& Stiles, 2013). In this study, we investigated setbacks as conceptualized by the assimilation model (Stiles, 2001, 2006, 2011) in two cases of Emotion-Focused Therapy (EFT; Elliott, Watson, Goldman, \& Greenberg, 2004; Greenberg, Rice, \& Elliott, 1993; Greenberg \& Watson, 2006).

Some authors have understood setbacks as an impediment to therapeutic progress (Engle \& Arkowitz, 2006; Leiper \& Kent, 2001; Omer, 1994; Wachtel, 1999). For example, Engle and Arkowitz (2006) described a setback as a "resistant ambivalence", which consists in "a subset of resistance in which there are movements towards change and movements away from change" (p.3). On the other hand, studies framed within the assimilation model have shown assimilation setbacks, at least, are often a normal part of the therapeutic progress (Caro Gabalda $\&$ Stiles, 2009, 2013). The alternation of advances and setbacks can yield sawtooth pattern of therapeutic progress (Osatuke et al., 2005, p.107). This more benign view is consistent with Mahoney's (1991) suggestion that human change processes are not smooth but punctuated by oscillations, back-and-forth movements, in which progresses and achievements are interspersed with setbacks.

\section{The Assimilation Model}

The assimilation model (Stiles, 2006, 2011; Stiles et al., 1990) suggests that clients' problematic experiences follow a regular developmental sequence as they 
move toward integration with the rest of the self in successful therapy. The model construes the self as a community of agentic voices, each of which represents traces of previous self-experiences (Honos-Webb \& Stiles, 1998; Stiles, Honos-Webb, \& Lani, 1999). Each voice tends to respond when it is addressed by life events; normally, this process brings the person's experiential resources to bear appropriately in everyday life. However, when life events address voices that represent problematic experiences or problematic relationships that are discrepant from the person's usual self, they may lead to psychological distress or maladaptive behavior or to suppression or avoidance of the problematic voice (Stiles, Osatuke, Glick, \& Mackay, 2004). Theoretically, these problematic, nondominant voices lack the meaning bridges that would give the dominant community of voices smooth access to them (Stiles, 2011).

The assimilation model suggests that progress in therapy is associated with the integration of the nondominant voices into the dominant community of voices (Honos-Webb \& Stiles, 1998; Osatuke \& Stiles, 2006). The sequence through which this integration is achieved is described in the eight stages of the Assimilation of Problematic Experiences Scale (APES; Stiles, 2001, 2005; Stiles et al., 1991), developed mainly through theory-building case study research. In the lowest stage of assimilation the nondominant voice is dissociated or avoided (stage 0 - warded off) and may emerge as physical symptoms. At the next stage, it may emerge into awareness but is immediately suppressed by the dominant voices (APES stage 1unwanted thoughts/avoidance). At APES stage 2 (vague awareness/emergence) the nondominant voice emerges unclearly but forcefully into awareness, bringing psychological suffering. At APES stage 3 (problem statement/clarification) the negative feelings persists as the nondominant voice and the dominant voice start to 
communicate allowing the client to have a clear statement of the problem and to differentiate the nondominant and dominant voices. At APES stage 4 (understanding/insight) the client has a clear understanding of the problematic experience and acknowledges the nondominant voice as a legitimate perspective. Meaning-bridge construction (Brinegar, Salvi, Stiles, \& Greenberg, 2006) facilitates a mutual understanding that suits both nondominant and dominant voices. The previously opposing voices come together within a new meaning at this stage. As assimilation progresses into the upper stages, the negative feelings dissipate, giving place to positive feelings. APES stage 5 (application /working through) involves client's application of the understanding in everyday life, and at APES stage 6 (problem solution) the client achieves a successful solution for his or her problem. As the problematic experience becomes fully integrated (APES stage 7 - mastery) and no longer a focus of attention, the affect becomes neutral. Once the problematic experiences become assimilated into the community of voices they become resources for the upcoming challenges and opportunities that life brings (Stiles, 2006).

Results reported by Detert, Llewelyn, Hardy, Barkham, and Stiles (2006) suggest that APES stage 4 (understanding/insight) is a dividing point between good and poor outcome as conventionally assessed using self-report symptom intensity measures. In that study, poor outcome clients never reached APES stage 4 on their major problems, whereas good outcome clients consistently reached APES 4 or higher. Theoretically, although the APES sequence is continuous, at stage 4, the feelings engendered by encountering the nondominant voice shift from primarily negative to primarily positive (Stiles et al., 2004). Theoretically, establishing a stable meaning bridge, which characterizes stage 4 , represents a turning point in the 
evolution of the dominant community's reaction to the problem from rigid and oppressive (in early APES stages), to welcoming (in later APES stages) (Osatuke \& Stiles, 2006).

\section{Setbacks in the Assimilation of Problematic Experiences}

Setbacks in assimilation can be defined as movements from higher stages to lower stages of the APES. For example, suppose a client expresses entitlement (representing the nondominant voice) "I need something different for my life, I'm feeling trapped at my parents' house, I need my space" (APES 3) and then starts to elaborate the difficulty and fear of confronting her parents (representing the dominant voice) "It's too too hard, I'll always think that if I take a decision that is against their (parents) will, that is too confusing for me."(APES 2). This movement from APES 3 to APES 2 constitutes a setback.

Conceptual considerations, prior to empirical investigation, suggested nine possible reasons for the occurrence of setbacks (see Stiles, 2005, for a list and explanations). This hypothetical list was reframed and condensed into three common categories: 1) Exceeding the therapeutic zone of proximal development; 2) Balance Strategy; 3) Spontaneous Switches, as a result of three case studies in which setbacks were identified and the reasons were classified (Caro Gabalda \& Stiles, 2009, 2013). Constructing this three-category classification of reasons for setbacks entailed an elaboration of the assimilation model's concept of problematic experience, according to which each problem consists of multiple strands (Caro Gabalda \& Stiles, 2013). The strands of a problem can be understood as interrelated subthemes or subtopics within a larger problematic theme or topic. Virtually all observed setbacks seemed to reflect a shift from one strand of a problem to another strand that was less advanced on the APES - a more difficult or distressing subtheme or one that had not received 
so much therapeutic attention. The following three categories distinguished by Caro Gabalda and Stiles (2013) reflect different kinds of pressures that led clients to switch strands.

\section{1) Exceeding the therapeutic zone of proximal development (ZPD).} Vygotsky's (1978) developmental concept of the ZPD was extended to the context of assimilation in psychotherapy by Leiman and Stiles (2001) to refer to the space between the stage of assimilation that the client can achieve on his or her own and the stage he or she can achieve in collaboration with the therapist. The therapeutic ZPD may be different for each problem and will move as the client makes progress on the problem. In order to promote novelty and progress in the assimilation process the therapist may press the client higher within the ZPD, but if the client feels this movement as too risky (exceeding the ZPD), he or she will move back into a less challenging stage of assimilation (Ribeiro, Ribeiro, Gonçalves, Horvath, \& Stiles, 2013; Ribeiro et al., 2015). Therapeutic work occurs within the therapeutic ZPD developed between client and therapist under joint collaboration.

2) Balance strategy (previously named balance metaphor; Caro Gabalda \& Stiles, 2013). The therapist intentionally directs the client's attention to less assimilated aspects of the problem to promote new understanding and change. In effect, the therapist acts to balance progress on one strand of the problem with attention to a less advanced strand. A setback occurs when the client follows the therapist's direction, attending to a strand that is at a lower APES stage. Promoting change and progress by redirecting client's attention to more difficult experiences is an expected part of the therapeutic process; indeed this sort of intervention is prescribed for some circumstances in some treatments. For example, in CBT this may occur when the therapist works on cognitive restructuring of negative automatic 
thoughts. In EFT balance-type setbacks may occur when the therapist is redirecting the client's attention to emotional painful experience that needs to be processed.

3) Spontaneous switches. These are moments when the client moves between voices without any apparent intervention from the therapist. The client is working on a particular strand of the problem at some APES level and then drops that strand to pick up another strand at an earlier APES stage. The client moves without any apparent intention to protect him or herself from painful experiences, as happens in exceeding the ZPD setbacks and without apparent external direction to difficult areas, as happens in balance strategy setbacks. To some extent, spontaneous switches is a residual category that entails movement to a different strand for reasons that were not clear to coders.

Note that in balance strategy setbacks, the client follows the therapist, whereas in ZPD setbacks the client fails to follow the therapist. In spontaneous switches the therapist makes no explicit intervention to prompt the backwards movement.

The three previous case studies concerning the analysis of setbacks were conducted on clients treated with Linguistic Therapy of Evaluation (LTE, a form of cognitive therapy; Caro Gabalda, 1996, 2002). Maria was diagnosed with generalized anxiety disorder and subclinical depressive symptoms, underwent 14 sessions of LTE and was considered a good outcome case (Caro Gabalda \& Stiles, 2009). Among Maria's 105 setbacks, ZPD was the most frequent reason (46.7\%), followed by balance strategy (35.2\%). Gabriel and Santi also presented with anxiety problems and were treated with LTE (Caro Gabalda \& Stiles, 2013; the case of Gabriel was also discussed by Caro Gabalda, Stiles, \& Pérez Ruiz, in press). Gabriel was considered a good outcome case; Santi was considered a poor outcome case. 
Gabriel's most frequent reason for setbacks was balance strategy (69.5\%); Santi's was exceeding the ZPD (59.3\%). Thus, in these three case studies, most setbacks were explained by balance strategy and exceeding the ZPD; in Maria's case they explained $82 \%$ of setbacks; in Gabriel's case they explained 94.3\%, and in Santi's case they explained $97.5 \%$.

It is important to note that all three reasons (i.e., virtually all setbacks in these three cases) describe activities that are a normal part of therapeutic work. That is, these studies' results were consistent both with the theoretical developmental sequence described by the APES and with the view that therapeutic progress often seems to proceed irregularly (because it switches from strand to strand). On the other hand, some previous studies have suggested that although assimilation progress presents frequent movements of back and forth in directive therapies, such as LTE and other cognitive therapies, progress is relatively smooth in nondirective, humanistic therapies (Honos-Webb, Stiles, Greenberg, \& Goldman, 1998; HonosWebb, Surko, Stiles, \& Greenberg, 1999; Osatuke, et al., 2005). EFT is humanistic but directive with respect to in-session processes (Elliott et al., 2004; Greenberg et al., 1993), and we thought investigating setbacks in EFT could help elaborate an understanding of how therapeutic approach affects the course of assimilation.

\section{Design and Purpose}

The present study was an intensive analysis of two cases treated with EFT. We chose one with good outcome and one with poor outcome by conventional criteria (see below), hoping to find a wide range of setback manifestations. Our purpose was to extend setbacks analysis to a different therapeutic approach (previously, setbacks had been studied only within LTE, as noted earlier). Selecting cases of EFT allowed us to explore the development of setbacks in a humanistic- 
experiential therapy. Our broader aim was to elaborate our theoretical understanding of how setbacks contribute to or detract from the process of assimilation. This was a theory-building study, so we were interested in how our observations conformed to the assimilation model or suggested modifications or elaborations, recognizing that any generalization proceeds from the theory, not from the results of these particular cases (Stiles, 2015; Stiles, Hill, \& Elliott, 2015).

\section{Method}

We studied two cases treated with EFT for depression at Instituto Universitário da Maia (ISMAI) in Portugal. The cases were drawn from the ISMAI Depression Project (Salgado, 2008), a randomized clinical trial for the treatment of mild to moderate depression, which compared CBT and EFT.

\section{Participants}

Alice and Barbara (pseudonyms) were selected as having had a good outcome and a poor outcome, respectively, based on standard symptom intensity measures, as described later. These two cases were randomly selected from a set of 10 goodoutcome and 10 poor-outcome cases from the EFT treatment group, which had complete transcripts for intensive process analyses. Both clients underwent an assessment that included the Structural Clinical Interview for the DSM-IV axis I (First, Spitzer, Gibbon \& Williams, 1996) and axis II (First, Sptizer, Gibbon, Williams \& Benjamin, 1997) as well as standard self-report measures of symptom severity and met diagnostic criteria for Major Depressive Disorder (MDD). They each received 16 weekly sessions of EFT in the ISMAI project.

Alice was a woman aged in her late 20s at the time she started therapy. She was the youngest of 3 siblings, living with her parents, who were very Catholic and conservative. At assessment, she was diagnosed with mild MDD. Alice was in a 
steady relationship for a few years and willing to get married. At the beginning of therapy her main clinically relevant theme was insecurity and lack of assertiveness across several important relationships, including her romantic relationship and relationships with her parents and with her boss. Alice started therapy feeling that her needs were not being met. She wanted to get married, and her boyfriend, who was not Catholic, just wanted to move in together. She presented with this conflict between wanting to keep her relationship and resenting that she was always giving in to her boyfriend's wishes, feeling herself disregarded because her needs were not being respected. Another clinical relevant theme was feeling hurt by her father; Alice experienced continuing difficulty dealing with how she and the family had coped with her father's past affair, a shared secret.

The therapist was a Portuguese female at her early thirties, who was an advanced doctoral student in clinical psychology, with 8 years of experience as a therapist. She had been pursuing training and gaining experience in EFT for the 4 years prior to this therapeutic process.

Barbara was a woman in her late 30s when she entered the project. She was at that time single and unemployed. At assessment, she was diagnosed with recurrent MDD and Avoidant Personality Disorder. The clinically relevant themes identified in Barbara's case were her difficulty exposing her feelings and emotions, feelings of sadness and loneliness, and her difficulty resolving the hurt resulting from the breakup with her ex-boyfriend. Barbara experienced an internal conflict between the need to feel loved and accepted and the fear of being rejected and abandoned. Barbara feared that if she expressed her feelings or ideas she would be rejected, leading to feelings of inadequacy and abandonment. The voice of her dominant community protected her from experiencing the rejection from others by convincing 
her to keep quiet. But this protectiveness from the dominant voice led Barbara to feel lonely and prevented her from accessing her core need to feel loved and taken care of ("I need to express what I feel and that does not mean to be ridiculous" and "some people love me for who I am").

Barbara's therapist was a Portuguese male with $\mathrm{PhD}$ in clinical psychology, with 20 years of experience as a clinical psychotherapist, training in EFT, and 5 years of experience in this therapeutic model.

\section{Treatment}

EFT therapists begin with the client-centered relational conditions (Rogers, 1957) and use experiential and gestalt interventions to facilitate the resolution of maladaptive affective-cognitive processing. These interventions included focusing (Gendlin, 1981) at a marker of an unclear felt sense, systematic evocative unfolding for problematic reactions, two-chair dialogue for self-evaluative and self-interruptive conflict splits and empty-chair dialogue for unfinished business with a significant other (Elliott, et al., 2004; Greenberg, et al., 1993; Greenberg \& Watson, 2006).

Therapists' adherence to EFT model was measured with the Experiential Therapy Adherence Measure (Goldman \& Greenberg, n.d.; Greenberg \& Watson, 1998). This observer rated measure entails three domains: general therapeutic skills (5 items); therapeutic tasks (21 items); and specific therapeutic actions (14 items), in which the items are rated from 0 to 7 . Adherence to the EFT protocol was assessed by two independent raters with previous training in EFT. The global Intraclass Correlation Coefficient (ICC) was 932 (Nogueira, Monteiro, Bento, Almeida, \& Salgado, 2012), indicating an excellent interrater reliability (Hill \& Lambert, 2004). The five therapists of the EFT treatment group showed a high level of adherence to EFT $(M=4.71 ; S D=1.56)$ suggesting a good incorporation of the procedural 
knowledge of the experiential principles of the model (Nogueira, et al., 2012).

\section{Outcome Measures}

Beck Depression Inventory II (BDI-II) (Beck, Steer, \& Brown, 1996). The BDI, a 21-item self-report instrument, assesses the severity of depressive symptoms (Beck et al., 1996; Steer, Brown, Beck, \& Sanderson, 2001), using a 4-point Likert scale, in which the items are rated from 0 to 3 ; total scores range from 0 to 63 . The BDI-II has exhibited good internal consistency $(\alpha=.91$; Steer et al., 2001; $\alpha=.89$; see Lopes et al., 2014) and construct validity (Beck et al., 1996; Steer et al., 2001). Validation for the Portuguese population has obtained results that were similar to the ones observed in the American population (Campos \& B. Gonçalves, 2011; Coelho, Martins, \& Barros, 2002). The cut-off point for Portuguese population is 14 points (Coelho et al., 2002). The Cronbach's Alpha was 0.89 and the Kaiser-Meyer-Olkin's (KMO) measure of sampling adequacy was 0.94 (Coelho et. al, 2002). Since the Reliable Change Index (RCI; Jacobson \& Truax, 1991) could not be found in Portuguese studies, we followed Bauer, Lambert and Nielsen (2004) suggestions and calculated this value based on the Cronbach's alpha $(\mathrm{RCI}=7.75)$.

OQ-45.2 (Lambert et al., 1996). The OQ-45.2, is a widely used self-report questionnaire for monitoring clients' progress in therapy. The OQ-45.2 is composed of 45 questions concerning psychological distress, interpersonal relations, and the clients' social role. Excellent internal consistency has been reported for Portuguese ( $\alpha=$.92; Machado \& Fassnacht, 2014) and non-Portuguese samples (de Jong et al., 2007; Lambert et al., 1996). A three-week test-retest reliability indicated a good temporal stability (Pearson $r=.84)($ Lambert et al., 1996). The cut off point for the Portuguese sample is 62 and the RCI (Jacobson \& Truax, 1991) for the OQ45.2 was calculated as 15 points for the total score (Machado \& Fassnacht, 2014). 


\section{Process Measures}

The APES (Stiles et al., 1991). This scale consists of eight stages that portray the assimilation of problematic experiences. Scale values range from 0 to 7 , as described earlier. For applying the APES in this study we used the Markers of Assimilation Manual developed by Lani and colleagues (2002), which includes twenty-six markers for distinguishing the eight stages. Each marker describes a type of clinical event that characterizes a particular stage and thus helps the raters to reliably classify passages of the client's discourse. In this context, a passage was a stretch of discourse on one topic at one APES stage containing no more than one APES marker. That is, each change of topic or APES stage or new APES marker initiated a new passage.

Setbacks (Caro Gabalda \& Stiles, 2009, 2013). A setback is scored each time a client drops at least one stage on the APES in successive passages. In this study, a setback was scored only if the return to a lower stage took place within the same speaking turn or in the client's first speaking turn that followed the therapist's first intervention. For example, suppose the therapist suggests a two-chair dialogue and asks:

$\mathrm{T}:$... What starts to happen to you when you try to imagine it?

C: I don't know. I start to get nervous and uncomfortable (APES 2)

T: Can you say a little more about those feelings? What is that nervousness, that uncomfortable feeling?

C: I just want it to end. I don't want to think about it...” (APES 1). For this study, reasons for setbacks were classified into four categories (see Table 1). These included the three used by Caro Gabalda and Stiles (2013), described earlier, plus one additional category developed in this study (see 
Procedures). Briefly, in a balance strategy setback, the therapist directs the client's attention to related material at a lower APES stage than the preceding passage, for example, with the intention to increase client's awareness and promote an alternative construction. In an exceeding the therapeutic ZPD induced by therapist (ZPD-T) setback, the therapist tries to move the client forward, but this movement oversteps the upper limit of the client's ZPD for the current material, and the client switches to related material at a lower APES stage. In an exceeding the therapeutic ZPD induced by client (ZPD-C) setback, the category developed in this study, the client follows the therapist's elaboration at a specific APES stage, but nevertheless oversteps the upper limit of the current strand's ZPD and switches to related material at a lower APES stage. That is, in a ZPD-C setback, raters judge that the client's own productions led to feeling threatened, thus exceeding the therapeutic ZPD. In this sense, the client moves toward safety within the therapeutic ZPD. Finally, in spontaneous switches the client shifts to less assimilated strands of the problem that did not seemed prompted by an intervention from the therapist or by exceeding the current strand's ZPD.

Caro Gabalda and Stiles (2013, p. 43) suggested several questions to help the raters understand what is happening in each setback: "What is the therapist doing?", "What is the client doing?", "What are therapist and client doing together?", "Is the therapist following the client?", "Is the client following the therapist?", “Are they talking about a new theme?", "From what perspective is the client talking - the nondominant or the dominant voice?". Raters are instructed to consider these questions each time a setback is identified to help them decide which reason best describes that retreat in the assimilation process.

\section{Procedures}


Outcome assessment and case selection. All clients in the ISMAI project completed the BDI-II and the OQ-45.2 at a pretreatment assessment and before sessions $1,4,8,12$ and 16 . We randomly selected the clients for this study from a pool of transcribed cases on the basis of their change from pre- to post-treatment assessment.

Alice, the good-outcome client showed reliable and clinically significant improvement (RCSI) on both measures according to criteria proposed by Jacobson and Truax (1991). On the BDI-II, she changed from 14 at pretreatment to 1 (below the clinical cutoff of 14) after session 16, a difference of 21 (greater than the RCI of 7.75). On the OQ-45.2, she changed from 86 at pretreatment to $39($ cutoff $=62)$ after session 16 , a change of $46(\mathrm{RCI}=15)$.

Barbara, the (relatively) poor-outcome client remained above the clinical cutoff on both measures and changed by less than the RCI on one of them. On the BDI-II, she scored 32 at pretreatment and 29 after session 16, a difference of only 3 points. On the OQ-45.2, she scored 115 at pretreatment and 93 after session 16, a difference of 22 points. Thus, although she did show some evidence of improvement, changing by an amount that exceeded the RCI of 15 on the OQ-45.2, she remained well into the clinical range on both measures.

Transcribing the sessions. The transcribers were undergraduate students who had 12 hours of training on the guidelines for the transcription of psychotherapy sessions (Mergenthaler \& Stinson, 1992). Five sessions were transcribed from each of the two therapeutic cases, specifically, sessions $1,4,8,12$ and 16 . The transcripts omitted names of people and places and other details that would identify the client. The sessions were transcribed and rated in Portuguese. The illustrative passages presented later were translated into English by this article's first author. 
APES and setbacks ratings. Our process rating procedures involved four major steps: 1. Identifying the clinically relevant themes and selecting relevant excerpts; 2. Distinguishing and describing the voices of the dominant community from the nondominant (problematic) voices; 3. Rating passages within each excerpt on the APES; and, 4. Classifying the reasons for setbacks in the assimilation process. Three individuals, all of whom are authors of this paper (first, second and fifth authors), served as raters for these steps. Two raters were in their middle 20s, one was a master student and the other a doctoral student, in clinical psychology, developing their postgraduate theses on topics regarding the assimilation model. The third rater was at her early 30s with a PhD in Clinical Psychology and extensive experience in qualitative coding. Two raters (various combinations of these three) worked on each task for each client, first doing each task individually and then meeting to discuss discrepancies and reach consensus.

In preparation for distinguishing voices and applying the APES, raters were trained by a doctoral student in clinical psychology with extensive experience in analyzing the assimilation process. First, the raters reviewed literature on the assimilation model and attended an introductory presentation regarding the APES and the markers of assimilation manual developed by Lani and colleagues (2002). Next, they coded four practice transcripts and met with the trainer to discuss and clarify doubts and disagreements concerning the coding. At the end of the training period, reliability of raters was assessed by comparing their codes with the codes of expert judges. Raters were considered reliable and able to engage in coding research material when they achieved an ICC higher than .70 (Hill \& Lambert, 2004).

1. Identifying clinical themes. The raters read and re-read the transcripts of the five sessions selected for each case, constructed a clinical formulation of the case, 
and identified clinically relevant (clinically poignant and recurrent) themes by consensual discussion. They then excerpted all passages dealing with the identified themes in the selected sessions of each case.

\section{Distinguishing the dominant and nondominant voices in each case.}

Following training in APES ratings, the raters re-read the transcripts and constructed a formulation of the dominant and nondominant voices for each case. Brief versions of the formulations were as follows:

Alice's major theme was a fear of being rejected and abandoned. This reflected Alice's dominant community impeding her expression of feelings and needs. The nondominant voices involved her own needs and assertiveness "I have the right to express myself and be accepted", "my parents need to accept what I want and decide for my life".

Barbara's dominant community of voices too was organized around themes of fear of expressing her feelings (e.g., "I cannot express what I feel”, "I need to protect myself") and feelings of inadequacy (“I don't appreciate myself"). Her main nondominant voices sought self-expression (e.g. "expressing what I feel does not mean to be ridiculous", "I have the right to show that I'm hurt" and "some people love me for who I am").

3. APES rating. After the voices were formulated, raters independently coded the five transcribed sessions from each case. They assigned an APES stage to each passage within each of the selected excerpts. Inter-rater reliability was ICC $=.97$ in the case of Alice and .81 in the case of Barbara; these ICCs are considered high (Finn, 1974, cited in Hill \& Lambert, 2004).

4. Setbacks analysis. After completing the assimilation analysis, raters carried out the setbacks analysis (Caro Gabalda \& Stiles, 2009, 2013; Stiles, 2005). 
The raters began with the case of Barbara (poor outcome case) using the nine reasons constructed conceptually and a priori by Stiles (2005). After a first review of the case, it appeared that all of the setbacks could be classified into the three categories found in the previous empirical studies by Caro Gabalda and Stiles $(2009,2013)$, and it was decided to use their conceptualization of setback reasons (described earlier) for the present study. Further examination, however, led to a refinement: A number of Barbara's (but not Alice's) setbacks fell in a subcategory of spontaneous switches that we now call exceeding the ZPD induced by client (ZPD-C), as contrasted with the earlier category, exceeding the ZPD induced by therapist (ZPD-T). Both are included in Table 1 . This addition makes a distinction within what had previously been called spontaneous switches, which was a residual category of setbacks not explained by therapist actions. These setbacks reflect the client reaching the limit of the current strand's ZPD without being pushed by the therapist.

Using the coding system shown in Table 1, the raters independently classified the setbacks in the excerpts (i.e., all instances of a drop of one or more APES stages in successive passages). After coding the setbacks from each session, raters met to discuss disagreements until they reached a consensus to establish a final coding. An inter-rater agreement based on the independent coding (Cohen's Kappa) was .80 for both cases, considered a good inter-rater reliability (Fleiss, 1981, cited in Hill \& Lambert, 2004).

\section{Results}

\section{Overview of Assimilation in the Two Cases}

Good outcome case. Alice showed both advances and setbacks in assimilation but with a clear positive trend across the five rated sessions (Figure 1). 
For the first half of therapy (sessions 1, 4, and 8), Alice alternated mainly between APES stages 2 and 3, reflecting the gradual emergence into awareness of the problematic experience of being assertive and expressing own needs. However a few passages were rated at APES stage 4, indicating moments of insight and the emergence of new meanings: Alice began to understand how her fear of being rejected impeded her expressing what she wanted and needed.

Later in therapy, expressions of understanding and insight (APES 4) and applying the new understanding (APES 5) were much more frequent. Alice acknowledged throughout therapy that her need to get married was linked to her parents' conservative and critical views, and she also expressed the need to be autonomous from her parents. This new understanding facilitated Alice's being able to confront her parents with her decision to move in with her boyfriend. Finally, towards the end of therapy, many passages were rated at APES stage 6, indicating a successful resolution of the problems and the integration of the previously nondominant voice of asserting her own needs into the community of voices ("I cannot care so much about what others may think in order to feel good"). That is, this previously problematic aspect of Alice had become a personal resource.

Poor Outcome case. Barbara's non-dominant voice of self-expression remained in lower APES stages $(1,2$, and 3) throughout therapy (Figure 2). No passages from the five rated sessions of Barbara's therapy reached APES stage 4 or higher. That is, the nondominant voice was clearly expressed, that is, the problem was stated explicitly (APES stage 3; e.g., "maybe it would be helpful if I let these feelings to come out" but "it won't solve anything if I express what I feel, so I prefer to keep quiet"). However, the opposed voices did not build a meaning bridge that could carry their mutual understanding (which would have been APES stage 4). 


\section{Setbacks in the Good Outcome Case}

We identified 26 setbacks in Alice's sessions (Table 2), of which 46\% were coded as balance strategy, $46 \%$ were coded as spontaneous switch, and only $8 \%$ were coded as ZPD-T. The low percentage of Alice's setbacks coded as ZPD-T implies that most of the time her therapist worked within her therapeutic ZPD.

The majority (73\%) of Alice's setbacks were small, dropping just one APES stage (e.g., from 4 to 3 , or from 3 to 2). Her larger setbacks (dropping two stages or more in adjacent passages) occurred mainly later in therapy (see Figure 1). Several of these occurred when, following a moment of understanding (APES 4), the therapist introduced an empty-chair dialogue. A setback of 3 stages, from APES 5 to APES 2, occurred in the last session, when Alice described an episode of new assertiveness and then shifted to her disappointment with her sister's lack of support for this (spontaneous switch).

The following excerpt from session 12 also illustrates a spontaneous switch setback. In session 12, Alice explored what she considered to be the turning point in her process of change. She had decided to do what was important to her and went on vacation with her boyfriend against her parents' wishes. This had led to her decision to move in with her boyfriend before getting married. In the excerpt, Alice described her new feeling of self-confidence, based on crediting her own wants and needs (higher APES stages) but she also explored her fears regarding her parents' reaction (lower APES stages). The movements between these strands did not seem to be prompted by any intervention from the therapist.

C: I decided to go on vacation, it made no sense to stay here (...)

$\mathrm{T}$ : Where do these differences come from?

C: Maybe because I'm more confident with myself, I can see things more clearly now...

T: What you want and need

C: What I want and what I need (APES 6). I remember that day I went for a 
coffee with my cousin and she said "go on vacation with him, move on with your life, you need your own space", and in fact I need that although I fear their [parents] reaction (APES 5).

Balance strategy setbacks were present in all of Alice's analyzed sessions. We present two examples to illustrate some of the variety in this type of setback, one from session 1, and another from session 16. Both excerpts concerned the core theme of assertiveness:

C: I went to him [boyfriend] and said "will you take much longer? And he said 'yes' "so I'm leaving" and then I spent the whole way home thinking "No, I have to say this" (T: mm-hm), I cannot hm pass up this situation in blank (APES 3)

$\mathrm{T}$ : How were you feeling when you went to him?

C: I was irritated

T: Irritated ok, where were you feeling this irritation?

C: A tightness in my heart, I was feeling irritated with that situation because we had agreed and that was something important for us hm and: I, we were not fulfilling [the agreement] (APES 2)

In this example the therapist turned the Alice's attention to more painful experiences involving less assimilated material. Alice followed the therapist's guidance to focus on her emotional experience and started to elaborate on it in collaboration with the therapist.

In the following excerpt from the final session Alice and her therapist were discussing her resolution of a self-interruptive split - one part of herself blocking the expression another part's emotional experience. When Alice began therapy she had great difficulty in expressing what she had felt earlier and continued to feel towards her father, in particular concerning her father's affair when she was a teenager. During therapy the therapist worked on this self-interruption using two-chair enactment (Elliott et al., 2004). As the conflict was resolved, Alice described the blocking part of herself as less powerful.

C: But at the same time I feel that she [self-interrupter part of herself] is small 
now! She does not have so much power! (APES 5)

T: exactly, it does not make you so anguished?

C: yes

$\mathrm{T}$ : in some way there is also a reason for that Alice [self-interrupter] to exist

$\mathrm{C}$ : yeah! I think that she is also right to feel angry and a part of her that does not accept, it's her right too, that concept that she had of the perfect family... I \pm think that she also has the right to feel that because she got hurt with all of this situation [father's past affair] (APES 3)

In this passage, the therapist tried to promote the negotiation between voices, checking whether or not the resolution of the conflict was a preemptive take-over of the self-interruptive part by the self-experiencer. As Alice followed the therapist she stepped back to a lower APES stage.

\section{Setbacks in the Poor Outcome Case}

We identified 27 setbacks in Barbara's sessions (Table 3), of which 53\% were coded as ZPD-T, $30 \%$ as balance strategy, and $18 \%$ as ZPD-C. No setbacks were identified in session 1, as all of the relevant passages were coded at APES stage 2 (see Figure 2). Most of the ZPD-T setbacks occurred in session 4. All of the setbacks were small (dropping just one stage), reflecting the relatively limited range of assimilation we observed in this case.

In session 4, the therapist encouraged Barbara to turn her attention inward and access her emotional experience. This strategy of, in effect, focusing on more difficult aspects of the current strand of the problem prompted many of the setbacks coded as ZPD-T. The following example from session 4 concerned Barbara's core theme, her fear of exposing herself. In this excerpt, Barbara and her therapist were discussing her difficulty in expressing her feelings:

T: "... Barbara, ok. - - While talking about it you are still getting sadder

C: (laughter)

$\mathrm{T}$ : almost as if you were granting permission to become sad

C: (laughter)

T: / (?: Breathe) 
C: - - - (tears in her eyes, cleans her own eyes with her hand) (APES 2)

$\mathrm{T}: \mathrm{mm}-\mathrm{hm}$ [(incomprehensible)] Barbara, the feeling I get is that you have a very painful feeling that needs to be heard. I know it's hard, very hard for you - very very hard - it took great courage to be here, in this moment, in these conditions - - but at the same time there is a pain that is not healed, only covered, trying to be smashed somehow

C: (cleans her eyes with her hand) but I don't know, I think, don't know if talking is going to change anything (...)

$\mathrm{T}$ : (...) often you have some difficulty facing what you feel

C: exactly, exactly, the fact that exposing things, to expose what we feel does not make the feelings disappear, does not allow us overcome them ...

"(APES 1)

As we understood it, the therapist was trying to help Barbara explore her emotional experience, in effect, directly addressing the nondominant voice.

Barbara's dominant community of voices actively resisted this attempt, minimizing the potential benefits. Barbara seemed to need to protect herself and moved to a lower stage of assimilation, shifting attention from her (tearful, inarticulate) feelings to a reason for not exploring.

Our final example was a setback coded as ZPD-C:

C: Sometimes I think that I would like to talk about everything, to expose everything, tell everything I feel, what I feel and was left unsaid.

T: mm-hm mm-hm

C: but on the other hand I think it makes no sense (APES 3) I don't know - I don't know I don't know." (APES 2)

As Barbara gave voice to the nondominant part of herself that wanted to be emotionally expressive (APES 3), she exceeded her own ZPD, and she visibly retreated. We inferred she was unable to tolerate this voice that expressed her needs and rights and moved towards safety, returning to APES stage 2 (feeling confused and distressed, saying “I don't know, I don't know”). Unlike ZPD-T setbacks, this instance of moving beyond the upper limit of ZPD, seemed to have come spontaneously from Barbara. 


\section{Discussion}

Replicating and extending previous studies on LTE (Caro Gabalda \& Stiles, 2009, 2013), our results showed setbacks as integral to assimilation progress in these two cases of EFT. As in the previous studies, most setbacks in APES stage could be attributed to either exceeding the client's therapeutic ZPD or to the therapist's use of a balance strategy. Interestingly, most setbacks in the poor outcome case (Barbara) were attributed to exceeding the ZPD, whereas most setbacks in the good outcome case (Alice) were attributed to the balance strategy or spontaneous switches. Since this latter subcategory was relatively rare in previous studies but very frequent in this good outcome case, we consider it further below.

In Barbara's case, there was a distinctively high frequency of ZPD-T in session 4 (see Table 3). EFT interventions are meant to bring into awareness the disregarded but healthy part of the self (Elliott et al., 2004), which within the assimilation model means bringing the nondominant voice into awareness. In Barbara's session 4, many such interventions were apparently experienced as a threat, which led her to shift to a safer strand of her experience (at a lower APES stage). However, in the subsequent coded sessions, this type of setback occurred only once. Perhaps the therapist responsively adjusted the intensity of his interventions to the client's ZPD (i.e., her tolerance for such pressure) as therapy progressed. Ribeiro, Ribeiro, et al. (2014) have suggested that therapists who fail to correctly sense their clients' ZPD limits may risk alliance ruptures and hamper therapeutic progress, whereas responsively adjusting to clients' tolerance for risk may help avoid or repair ruptures (Eubanks-Carter, Muran, \& Safran, 2015).

By contrast, in the case of Alice, there were only two instances of setbacks 
due to ZPD-T. We suggest that Alice's therapist worked within her therapeutic ZPD more consistently. Thus in both cases the therapist seemed to be following the EFT principle of remaining close to the client's moment-by-moment experience. By responsive adjustment of interventions to the client's pace and ZPD the therapist can create opportunities for destabilizing and replacing maladaptive interpersonal patterns (Safran \& Muran, 2000).

Barbara presented comorbid avoidant personality difficulties, and this may help explain her failure to make assimilation progress in this short-term treatment. There is growing acceptance that personality disorders involve deficiencies in metacognition and mentalizing, that is, an ability to recognize, focus on, and understand one's own mental states as well as the mental states of others (Allen \& Fonagy, 2006; Bateman \& Fonagy, 2006; Dimaggio, Carcione, Salvatore, Semerari, \& Nicolò, 2010; Dimaggio \& Lysaker, 2015; Dimaggio, Semerari, Carcione, Nicolò, \& Procacci, 2007; Osatuke, Stiles, Barkham, Hardy, \& Shapiro, 2011). Such deficiencies are evidenced by difficulties in acknowledging one's own thoughts and emotions and in identifying the causes behind one's emotions (Bateman \& Fonagy, 2006; Fiore, Dimaggio, Nicolò, Semerari, \& Carcione, 2008; Procacci, Popolo, Petrilli, \& Dimaggio, 2007). Perhaps moving the ZPD up the APES made greater demands on metacognitive and mentalizing abilities than Barbara could muster in 16 sessions.

The construction of ZPD-C as a new category of setbacks could be considered as an instance of abduction in theory-building research (Stiles, 2009). That is, our new observations have tentatively elaborated our theoretical understanding of setbacks within the assimilation model. The ZPD-C setbacks involved Barbara's testing her own upper limits and then shifting to a different strand 
when the testing became threatening. This return to former developmental levels within the ZPD may be seen as "self-protective processes that serve to maintain the coherence of a living system" (Mahoney, 2000, p.46). The concept of setbacks due to exceeding therapeutic ZPD (either induced by therapist or by client) is akin to the concept of return to the dominant narrative (Gonçalves et al., 2011; Ribeiro, Mendes, et al., 2014), which conceives these movements as "self-protective mechanisms to manage the felt risk of contradicting" the dominant community of voices (Ribeiro, Ribeiro, et al., 2014, p.356).

In successful cases, therapeutic collaboration should encourage the movement of the client's ZPD as therapy progresses (Ribeiro et al., 2013; Zonzi et al., 2014); theoretically, "what was formerly a potential level becomes an actual level and extends the client's potential level towards greater capacity" to assimilate and further integrate the nondominant voice (Ribeiro et al., 2013, p.298). Presumably, Alice's low level of ZPD-T setbacks despite therapist interventions at progressively higher levels reflected movement of her ZPD, as previously potential levels became current developmental levels.

Exceeding the client's ZPD may briefly reverse progress, but it can be helpful in some cases. In a good outcome case of EFT, Ribeiro and colleagues (2015) found that more challenging interventions (i.e. pushing the client to the upper limit of her ZPD) in the middle phase of treatment was associated with progress on the APES. On the other hand, clients who present greater difficulties in exploring their painful experiences may have a relatively narrow ZPD; "when the zone [ZPD] is too narrow, there is no place to play, and therapeutic progress is slow and difficult" (Zonzi et al., 2014, p.459). Therapists may need to work on their own impatience to accept the pace of such clients' work within their own therapeutic ZPD. 
Balance strategy setbacks, the most frequent type in Alice case, represent a shift to less advanced strands of a problem in response to the therapist's directive interventions. Presumably, Alice's attention to less assimilated strands of her problem promoted understanding and change across a wider spectrum of interrelated issues. Caro Gabalda and colleagues (in press) also observed that balance setbacks were associated with therapeutic progress and change in the case they studied. In contrast to Barbara, Alice may have started therapy with higher metacognitive or metalizing abilities, or may have developed these as therapy progressed. The relation of metacognitive abilities to assimilation progress could constitute an interesting direction for future research.

Awareness, exploration and reflection regarding emotional experience fosters self-understanding and problem solving (Klein, Mathieu-Coughlan, \& Kiesler, 1986). Alice and Barbara exhibited different emotional processing abilities; in contrast to Barbara, Alice seemed more able to deepen and explore her inner emotional experience and, therefore, to process her maladaptive emotions and access her primary adaptive emotions and core needs. Research on the depth of emotional processing suggests that clients with higher levels of emotional processing have better therapeutic outcomes (Castonguay, Goldfried, Wiser, Raue, \& Hayes 1996; Goldman, Greenberg, \& Pos, 2005; Watson \& Bedard, 2006). In experiential therapies this ability to move deeply into internal experience is a predictor of change in depressive symptoms (Goldman, et al., 2005; Yeryomenko, 2012).

Spontaneous switch setbacks were common in Alice's case, mainly in session 12 (see Table 2), whereas in the previous research in LTE, this category was rare (Caro Gabablda \& Stiles, 2013; Caro Gabalda et al., in press). EFT entails a process of following and leading (Elliott \& Greenberg, 2007) where the therapist guides the 
client to work on relevant emotional problem markers but, at the same time, follows the client as he or she is always the expert of own experience. The following aspect may have made the occurrence of spontaneous switch setbacks more likely than in LTE, which is a more explicitly directive approach.

\section{Summary and Limitations}

Of course, our observations on the cases of Alice and Barbara do not, by themselves justify generalizations to other cases, and our interpretations are necessarily tentative. That said, in theory-building research, the range of generality is specified by the theory rather than inferred from a study's method (Stiles, 2009, 2015; Stiles et al., 2015). Assimilation theory, for example, describes the range of phenomena it seeks to explain. Observations may increase or decrease confidence in the theory or suggest ways to tentatively revise or elaborate the theory (abductions), but they are not meant to be generalized as isolated statements.

The observations that Alice's assimilation ratings increased substantially whereas Barbara's didn't are consistent with theoretical expectations for good- and poor-outcome cases, respectively. More qualitatively, the transformation of Alice's voice of self-assertion from a problem into a resource was consistent with the assimilation model's account of psychological change. Finding that most of both clients' setbacks could be described using the previously developed categories, balance strategy and ZPD-T was consistent with assimilation account developed previously (Caro Gabalda \& Stiles, 2013), while the addition of the ZPD-C category represents a theoretically-consistent elaboration. Finding that setbacks in cases of EFT followed patterns similar to those in LTE was consistent with the theoretical contention that similar assimilation processes characterize change in all therapies. The relatively low incidence of ZPD-T setbacks in Alice's therapy invites the 
interpretation that the therapist skillfully stayed within Alice's ZPD. This support and elaboration in these cases justify a small increment in confidence in assimilation theory.

There are also further reasons to be tentative. The restricted number of sessions (5 out of 16) analyzed constitutes a limitation; analysis of all sessions could have yielded different results. Rater biases were possible, insofar as the raters were also authors and arguably had an interest in supporting the theory. Further research is needed to evaluate the tentative theoretical suggestions in a wider variety of cases and treatment approaches.

\section{Clinical implications}

Our results support the theoretical suggestion that the therapists' attunement to client's ZPD is central and that setbacks are an integral part of the process of joint exploration. This raises the clinical question of how therapists can stay close to clients' experience and at the same time extend clients' ZPD. The collaboration of client and therapist in moving the therapeutic ZPD is worthy of further investigation. 


\section{References}

Allen, J. G. \& Fonagy, P. (Eds.) (2006). Handbook of Mentalization-Based Treatment. West Sussex: John Wiley \& Sons, Ltd.

Barkham, M., Shapiro, D. A., Hardy, G. E., \& Rees, A. (1999). Psychotherapy in two-plus-one sessions: Outcomes of a randomized controlled trial of cognitive-behavioural and psychodynamic-interpersonal therapy for subsyndromal depression. Journal of Consulting and Clinical Psychology, 67, 201-211. doi:10.1037/0022-006X.67.2.201

Bateman, A. \& Fonagy, P. (2006). Mentalization-Based Treatment for Borderline Personality Disorder. New York: Oxford University Press

Bauer, S., Lambert, M. J., \& Nielsen, S. L. (2004). Clinical significance methods: A comparison of statistical techniques. Journal of Personality Assessment, 82, $60-70$.

Beck, A. T., Steer, R. A., \& Brown, G. K. (1996). Manual for the Beck Depression Inventory-II (BDI-II). San Antonio, TX: Psychological Corporation.

Brinegar, M. G., Salvi, L. M., Stiles, W. B., \& Greenberg, L. S. (2006). Building a meaning bridge: Therapeutic progress from problem formulation to understanding. Journal of Counseling Psychology, 53, 165-180. doi: 10.1037/0022-0167.53.2.165

Campos, R. C., \& Gonçalves, B. (2011). The Portuguese Version of the Beck Depression Inventory-II (BDI-II). European Journal of Psychological Assessment, 27, 258-264. doi: 10.1027/1015-5759/a000072

Caro Gabalda, I. (1996). The linguistic therapy of evaluation: A perspective on language in psychotherapy. Journal of Cognitive Psychotherapy, 10, 83-104.

Caro Gabalda, I. (2002). An introduction to the linguistic therapy of evaluation. In I. 
Caro \& C. Read (Eds.), General semantics in psychotherapy (pp. 154_181). New York: Institute of General Semantics.

Caro Gabalda, I. \& Stiles, W. B. (2009). Retrocessos no contexto de terapia linguística de avaliação [Setbacks in the context of linguistic therapy of evaluation] Irregular assimilation progress: Reasons for setbacks in the context of linguistic therapy of evaluation. Análise Psicológica, 2, 199-212.

Caro Gabalda, I. \& Stiles, W. B. (2013). Irregular assimilation progress: Reasons for setbacks in the context of linguistic therapy of evaluation. Psychotherapy Research, 23, 35-53. doi: 10.1080/10503307.2012.721938

Caro Gabalda, I. \& Stiles, W. B., \& Pérez Ruiz, S. (in press) Therapeutic activities in the assimilation process. Psychotherapy Research.

Castonguay, L. G., Goldfried, M. R., Wiser, S., Raue, P. J., \& Hayes, A. M. (1996). Predicting the effect of cognitive therapy for depression: a study of unique and common factors. Journal of Consulting and Clinical Psychology, 64(3), 497-504. Disponível em http://www.ncbi.nlm.nih.gov/pubmed/8698942.

Coelho, R., Martins, A., \& Barros, H. (2002). Clinical profiles relating gender and depressive symptoms among adolescents ascertained by the Beck Depression Inventory II. European Psychiatry, 17, 222-226.

De Jong, K., Nugter, M. A., Polak, M. G., Wagenborg, J. E. A., Spinhoven, P., \& Heiser, W. J. (2007). The outcome questionnaire (OQ-45) in a Dutch population: A cross-cultural validation. Clinical Psychology \& Psychotherapy, 14, 288-301. doi:10.1002/cpp.529

Detert, N. B., Llewelyn, S., Hardy, G. E., Barkham, M., \& Stiles, W. B. (2006). Assimilation in good- and poor-outcome cases of very brief psychotherapy for mild depression: An initial comparison. Psychotherapy Research, 16(4), 393407. doi:10.1080/10503300500294728 
Dimaggio, G., Carcione, A., Salvatore, G., Semerari, A., \& Nicolò, G. (2010). A rational model for maximizing the effects of therapeutic relationship regulation in personality disorders with poor metacognition and over-regulation of affects. Psychology and Psychotherapy: Theory, Research and Practice, 83, 363-384. doi: $10.1348 / 147608310 X 485256$

Dimaggio, G., \& Lysaker, P. H. (2015). Metacognition and Mentalizing in the psychotherapy of patients with psychosis and personality disorders. Journal of Clinical Psychology: In Session, 71(12), 117-124. doi: 10.1002/jclp.22147

Dimaggio, G., Semerari, A., Carcione, A., Nicolò, G., \& Procacci, M. (2007). Psychotherapy of personality disorders: Metacognition, states of mind and interpersonal cycles. Routledge. doi:10.1002/cpp.555

Elliott, R. \& Greenberg, L.S. (2007). The essence of Process-Experiential/EmotionFocused Therapy. American Journal of Psychotherapy, 61, 241-254.

Elliott, R., Watson, J. C., Goldman, R., \& Greenberg, L. S. (2004). Learning emotionfocused therapy: the process-experiential approach to change. Washington, DC: American Psychological Association. doi: 10.1037/10725-000

Engle, D., \& Arkowitz, H. (2006). Ambivalence in psychotherapy. Facilitating readiness to change. New York: Guilford Press.

Eubanks-Carter, C., Muran, J. C., \& Safran, J. (2015). Alliance-focused training. Psychotherapy, 52, 169-173. doi:10.1037/a0037596

Fiore, D., Dimaggio, G., Nicoló, G., Semerari, A., \& Carcione, A. (2008). Metacognitive interpersonal therapy in a case of obsessive-compulsive and avoidant personality disorders. Journal of clinical psychology, 64, 168-180. doi: $\underline{10.1002 / j \mathrm{jlp} .20450}$

First, M.B., Gibbon M., Spitzer R.L., Williams, J.B.W., Benjamin L.S. (1997). 
Structured Clinical Interview for DSM-IV Axis II Personality Disorders, (SCID-

II). Washington, D.C.: American Psychiatric Press, Inc.

First, M. B., Spitzer, R. L, Gibbon M. W., \& Williams, J. B. W. (1996) Structured Clinical Interview for DSM-IV Axis I Disorders, Clinician Version (SCID-CV). Washington, D.C.: American Psychiatric Press, Inc.

Gendlin, E. T. (1981). Focusing ( $2^{\text {nd }}$ ed). New York: Bantam Books.

Gonçalves, M. M., Ribeiro, A. P., Stiles, W. B., Conde, T., Matos, M., Martins, C., \& Santos, A. (2011). The role of mutual in-feeding in maintaining problematic self-narratives: Exploring one path to therapeutic failure. Psychotherapy Research, 21, 27-40. doi: 10.1080/10503307.2010.507789

Goldman, R., \& Greenberg, L. (n.d.). Experiential Therapy Adherence Measure. Unpublished material. Goldman, R. N., Greenberg, L. S., \& Pos, A. E. (2005). Depth of emotional experience and outcome. Psychotherapy Research, 15, 248260. doi:10.1080/10503300512331385188.

Greenberg, L. S., Rice, L. N., \& Elliott, R. (1993). Facilitating Emotional Change: The Moment-by-Moment Process. New York: Guilford. doi: 10.1037/11286000

Greenberg, L., \& Watson, J. (1998). Experiential therapy of Depression: Differential effects of client-centered relationship conditions and process experiential interventions. Psychotherapy Research, 8, 210-224.

doi:10.1080/10503309812331332317 Greenberg, L. S., \& Watson, J. C. (2006). Emotion-Focused Therapy for Depression. Washington: American Psychological Association.

Hill, C. E., \& Lambert, M. J. (2004). Methodological issues in studying psychotherapy processes and outcomes. In M. J. Lambert (Ed.), Handbook of psychotherapy and behavior change (5th ed., pp. 84-135). New York: Wiley. 
Honos-Webb, L., \& Stiles, W.B. (1998). Reformulation of assimilation analysis in terms of voices. Psychotherapy, 35, 23 - 33. doi: 10.1037/h0087682

Honos-Webb, L., Stiles, W., Greenberg, L. \& Goldman, R. (1998). Assimilation Analysis of Process-Experiential Psychotherapy: A Comparison of Two Cases. Psychotherapy Research, 8:3, 264 - 286. doi: 10.1093/ptr/8.3.264

Honos-Webb, L., Surko, M., Stiles, W.B., \& Greenberg, L.S. (1999). Assimilation of voices in psychotherapy: The case of Jan. Journal of Counseling Psychology, 46, 448-460. doi: 10.1037/0022-0167.46.4.448

Jacobson, N. S., \& Truax, P. (1991). Clinical Significance: A statistical approach to defining meaningful change in psychotherapy research. Journal of Consulting and Clinical Psychology, 59, 12-19. doi:10.1037/0022-006X.59.1.1

Klein, M., Mathieu-Coughlan, P., \& Kiesler, D., (1986). The Experiencing Scales. In L.S. Greenberg \& W. Pinsof (Eds.), The Psychotherapeutic Process: A Research Handbook (pp. 21-66). New York: Guilford Press

Lambert, M. J., Burlingame, G. M., Umphress, V., Hansen, N. B., Vermeersch, D. A. Clouse, G. C., \& Yanchar, S. C. (1996). The reliability and validity of the Outcome Questionnaire. Clinical Psychology \& Psychotherapy, 3, 249-258. doi: 10.1002/(SICI)1099-0879(199612)

Lani, J. A., Glick, M.J., Osatuke, K., Brandenburg, C., Gray, M. A., Humphreys, D.R., \& Stiles, W.B. (2002) Markers of Assimilation Manual. Department of Psychology: Miami University.

Leiman, M., \& Stiles, W. B. (2001). Dialogical Sequence Analysis and the Zone of Proximal Development as Conceptual Enhancements to the Assimilation Model: The Case of Jan Revisited. Psychotherapy Research, 11(3), 311-330. doi: $10.1080 / 713663986$ 
Leiper, R., \& Kent, R. (2001). Working through setbacks in psychotherapy. London: Sage.

Lopes, R. T., Gonçalves, M. M., Machado, P. P. P., Sinai, D., Bento, T., \& Salgado, J. (2014). Narrative Therapy vs. Cognitive-Behavioral Therapy for moderate depression: Empirical evidence from a controlled clinical trial. Psychotherapy Research, 24, 662-674. doi: 10.1080/10503307.2013.874052

Machado, P. P., \& Fassnacht, D. (2014). The Portuguese version of the Outcome Questionnaire (OQ-45): Normative data, reliability, and clinical significance cut-offs scores. Psychology and Psychotherapy: Theory, Research and Practice. doi: 10.1111/papt.12048

Mahoney, M.J. (1991). Human Change Processes: The Scientific Foundations of Psychotherapy. Basic Books.

Mahoney, M. (2000). Core ordering and disordering processes: A constructive view of psychological development. In R. A. Neimeyer \& J. A. Raskin (Eds), Constructions of disorder: Meaning-making frameworks for psychotherapy (pp.43-62). Washington, DC: APA.

Mergenthaler, E., \& Stinson, C. (1992). Psychotherapy transcription standards: Psychotherapy Research, 2, 125-142. doi: 10.1080/10503309212331332904

Nogueira, D., Monteiro, M., Bento, T., Almeida, C., \& Salgado, J. (2012, October). Therapists Adherence to Emotion Focused Therapy within a comparative RCT of depression treatments. Paper presented at the 3rd Joint Meeting of Society for Psychotherapy Research European and UK Chapters, Porto, Portugal.

Omer, H. (1994). Critical interventions in psychotherapy. New York: Norton.

Osatuke, K., Glick, M. J., Stiles, W. B., Greenberg, L. S., Shapiro, D. A., \& Barkham, M. (2005). Temporal patterns of improvement in client-centred 
therapy and cognitive-behaviour therapy. Counselling Psychology

Quarterly, 18, 95-108. doi: 10.1080/09515070500136900

Osatuke, K., \& Stiles, W.B. (2006). Problematic internal voices in clients with borderline features: An elaboration of the assimilation model. Journal of Constructivist Psychology, 19, 287-319. doi: 10.1080/10720530600691699

Osatuke, K., Stiles, W. B., Barkham, M., Hardy, G. E., \& Shapiro, D. A., (2011). Relationship between mental states in depression: The assimilation model perspective. Psychiatry Research, 190, 52-59. doi:10.1016/j.psychres.2010.11.001

Procacci, M., Popolo, R., Petrilli, D., \& Dimaggio, G. (2007). Avoidant Personality Disorder: Model and treatment. In G. Dimaggio \& A. Semerari with A. Carcione, G. Nicolò, \& M. Procacci (Eds), Psychotherapy of Personality Disorder: Metacognition, states of mind and interpersonal cycles (pp. 153-187). London: Routledge.

Ribeiro, A. P., Mendes, I., Stiles, W. B., Lynne, A., Sousa, I., \& Gonçalves, M. M., (2014). Ambivalence in emotion-focused therapy for depression: The maintenance of problematically dominant self-narratives. Psychotherapy Research, 24, 702-710. doi: 10.1080/10503307.2013.879620

Ribeiro, E. M., Cunha, C., Teixeira, S. T., Pires, N., Santos, B., Basto, I., Salgado, J., Stiles, W. B. (2015). Therapeutic collaboration and the assimilation of problematic experiences in emotion-focused therapy for depression: Comparison of two cases. Manuscript submitted for publication.

Ribeiro, E. M., Ribeiro, A. P., Gonçalves, M. M., Horvath, A. O., \& Stiles, W. B. (2013). How collaboration in therapy becomes therapeutic: The Therapeutic Collaboration Coding System. Psychology and Psychotherapy: Theory, 
Research, and Practice, 86, 294-314. doi: 10.1111/j.2044-8341.2012.02066.x

Ribeiro, A. P., Ribeiro, E., Loura, J., Gonçalves, M. M., Stiles, W. B., Horvath, A. O., \& Sousa, I. (2014). Therapeutic collaboration and resistance: Describing the nature and quality of the therapeutic relationship within ambivalence events using the Therapeutic Collaboration Coding System. Psychotherapy Research, 24, 346-359, doi: 10.1080/10503307.2013.856042

Rogers, C. R. (1957). The necessary and sufficient conditions of therapeutic personality change. Journal of Consulting Psychology, 21, 95-103.

Safran, J. D. \& Muran, J. C. (2000). Negotiating the therapeutic alliance, A relational treatment guide. The Guilford Press.

Salgado, J. (2008). Decentering and change: Grant project PTDC/PSI PCL/103432/2008. Unpublished manuscript. FCT: Portuguese Foundation for Science and Technology.

Seggar, L. B., Lambert, M. J., \& Hansen, N. B. (2002). Assessing clinical significance: application to the Beck Depression Inventory. Behavior Therapy, 33, 253-269. doi:10.1016/S0005-7894(02)80028-4

Steer, R. A., Brown, G. K., Beck, A. T., \& Sanderson, W. C. (2001). Mean Beck Depression Inventory-II scores by severity of major depressive episode. Psychological Reports, 88, 1075-1076. doi:10.2466/pr0.2001.88.3c.1075

Stiles, W. B. (2001). Assimilation of problematic experiences. Psychotherapy, 38, 462-465. doi: 10.1037/0033-3204.38.4.462

Stiles, W.B. (2005). Extending the Assimilation of Problematic Experiences Scale: Commentary on the special issue. Counselling Psychology Quarterly, 18, 8594. doi: 10.1080/09515070500136868

Stiles, W. B. (2006). Assimilation and the process of outcome: Introduction to a 
special section. Psychotherapy Research, 16, 389-392. doi:

$10.1080 / 10503300600735497$

Stiles, W. B. (2007). Theory-building case studies of counselling and psychotherapy. Counselling and Psychotherapy Research, 7, 122-127. doi: $10.1080 / 14733140701356742$

Stiles, W.B. (2011). Coming to terms. Psychotherapy Research, 21, 367-384. doi: $10.1080 / 10503307.2011 .582186$

Stiles, W. B. (2015). Theory-building, enriching, and fact-gathering: Alternative purposes of psychotherapy research. In O. Gelo, A. Pritz, \& B. Rieken (Eds.), Psychotherapy research: General issues, process, and outcome (pp. 159-179). New York: Springer-Verlag.

Stiles, W. B., Elliott, R., Llewelyn, S. P., Firth-Cozens, J. A., Margison, F. R., Shapiro, D. A., \& Hardy, G. (1990). Assimilation of problematic experiences by clients in psychotherapy. Psychotherapy, 27, 411 - 420. doi: 10.1037/00333204.27.3.411

Stiles, W. B., Hill, C. E., \& Elliott, R. (2015). Looking both ways. Psychotherapy Research, 25, 282-293. doi: 10.1080/10503307.2014.981681

Stiles, W. B., Honos-Webb, L., \& Lani, J. A. (1999). Some functions of narrative in the assimilation of problematic experiences. Journal of Clinical Psychology, $55,1213-1226$.

Stiles, W.B., Morrison, L.A., Haw, S.K., Harper, H., Shapiro, D.A., \& Firth-Cozens, J. (1991). Longitudinal study of assimilation in exploratory psychotherapy. Psychotherapy, 28, 105-206. doi: 10.1037/0033-3204.28.2.195

Stiles, W. B., Osatuke, K., Glick, M. J., \& Mackay, H. C. (2004). Encounters between internal voices generate emotion: An elaboration of the assimilation 
model. In H. H. Hermans \& G. Dimaggio (Eds.), The dialogical self in psychotherapy (pp. 91-107). New York: Brunner-Routledge.

Watson, J. C., \& Bedard, D. L. (2006). Clients' emotional processing in psychotherapy: a comparison between cognitive-behavioral and process-experiential therapies. Journal of Consulting and Clinical Psychology, 74(1), 152-159. doi:10.1037/0022-006X.74.1.152

Vygotsky, L.S. (1978). Mind in society: the development of higher psychological processes. Harvard University Press.

Wachtel, P. L. (1999). Resistance as a problem for practice and theory. Journal of Psychotherapy Integration, 9, 103-118. doi:10.1023/A:1023262928748

Zonzi, A., Barkham, M., Herdy, G. E., Llewelyn, S. P., Stiles, W. B., Leiman, M. (2014). Zone of proximal development (ZPD) as an ability to play in psychotherapy: A theory-building case study of very brief therapy. Psychology and Psychotherapy: Theory, Research and Practice, 87, 447-464. doi:10.1111/papt.12022

Yeryomenko, N. (2012). Does the depth of client experiencing predict good psychotherapy outcomes? A meta-analysis of treatment outcomes (Unpublished master's thesis). University of Windsor, Ontario, Canada. 
Table 1

Revised Reconceptualization of Setbacks

\begin{tabular}{|c|c|c|}
\hline \multicolumn{2}{|c|}{ Multiple Strands of a problem } & \multirow[b]{2}{*}{$\begin{array}{l}\text { Examples } \\
\text { Client (C): “... I feel I can } \\
\text { distance myself much more } \\
\text { than I used too and I realized I } \\
\text { don't want to be around those } \\
\text { people. (APES 3). } \\
\text { Therapist (T): You realized } \\
\text { you don't want to be around } \\
\text { them as you became more } \\
\text { analytical. What feelings does } \\
\text { that bring to you? } \\
\text { C: I become disappointed } \\
\text { because I feel we are not in } \\
\text { the same path...” (APES 2) }\end{array}$} \\
\hline Balance Strategy & $\begin{array}{l}\text { Therapist directs } \\
\text { client's attention to } \\
\text { less assimilated } \\
\text { experiences from } \\
\text { what they have } \\
\text { been previously } \\
\text { discussing. }\end{array}$ & \\
\hline $\begin{array}{l}\text { Exceeding the } \\
\text { therapeutic Zone of } \\
\text { Proximal } \\
\text { Development } \\
\text { induced by therapist } \\
\text { (ZPD-T) }\end{array}$ & $\begin{array}{l}\text { Therapist intends to } \\
\text { promote clients' } \\
\text { elaboration to } \\
\text { higher APES stages } \\
\text { but, when clients } \\
\text { are pushed beyond } \\
\text { the limit of their } \\
\text { tolerance, they } \\
\text { return to a less } \\
\text { assimilated stage. }\end{array}$ & $\begin{array}{l}\text { C: “...I want to express } \\
\text { myself but I can't because } \\
\text { people would become } \\
\text { annoyed with me. (APES 3) } \\
\text { T: So let's do it. Let's annoy } \\
\text { them, let's express how you } \\
\text { feel to them. (switches chair) I } \\
\text { would like you to imagine one } \\
\text { of those persons in that } \\
\text { chair... What would you like } \\
\text { to tell him or her? } \\
\text { C: I think I am not able to do } \\
\text { that... I think it's not worth it } \\
\text { because it won't change } \\
\text { anything...” (APES 2) }\end{array}$ \\
\hline $\begin{array}{l}\text { Exceeding the } \\
\text { therapeutic Zone of } \\
\text { Proximal } \\
\text { Development } \\
\text { induced by client } \\
\text { (ZPD-C) }\end{array}$ & $\begin{array}{l}\text { The presence of the } \\
\text { nondominant voice } \\
\text { is, at some point, } \\
\text { felt at the upper } \\
\text { limit of own ZPD. } \\
\text { Without any } \\
\text { intervention from } \\
\text { the therapist, the } \\
\text { client moves to a } \\
\text { lower APES stage. }\end{array}$ & $\begin{array}{l}\text { C: "Maybe I'm happy with } \\
\text { myself for having said no to } \\
\text { him (ex-boyfriend) for the } \\
\text { first time because before I } \\
\text { wouldn't even think of doing } \\
\text { it. (APES 3) But at the same } \\
\text { time... I don't know... I don't } \\
\text { know if I said no to him } \\
\text { because I'm postponing the } \\
\text { situation or if I don't have } \\
\text { feelings for him, anymore. I'm } \\
\text { confused..." (APES 2) }\end{array}$ \\
\hline Spontaneous Switch & Client focus on a & C: “...When I am with those \\
\hline
\end{tabular}




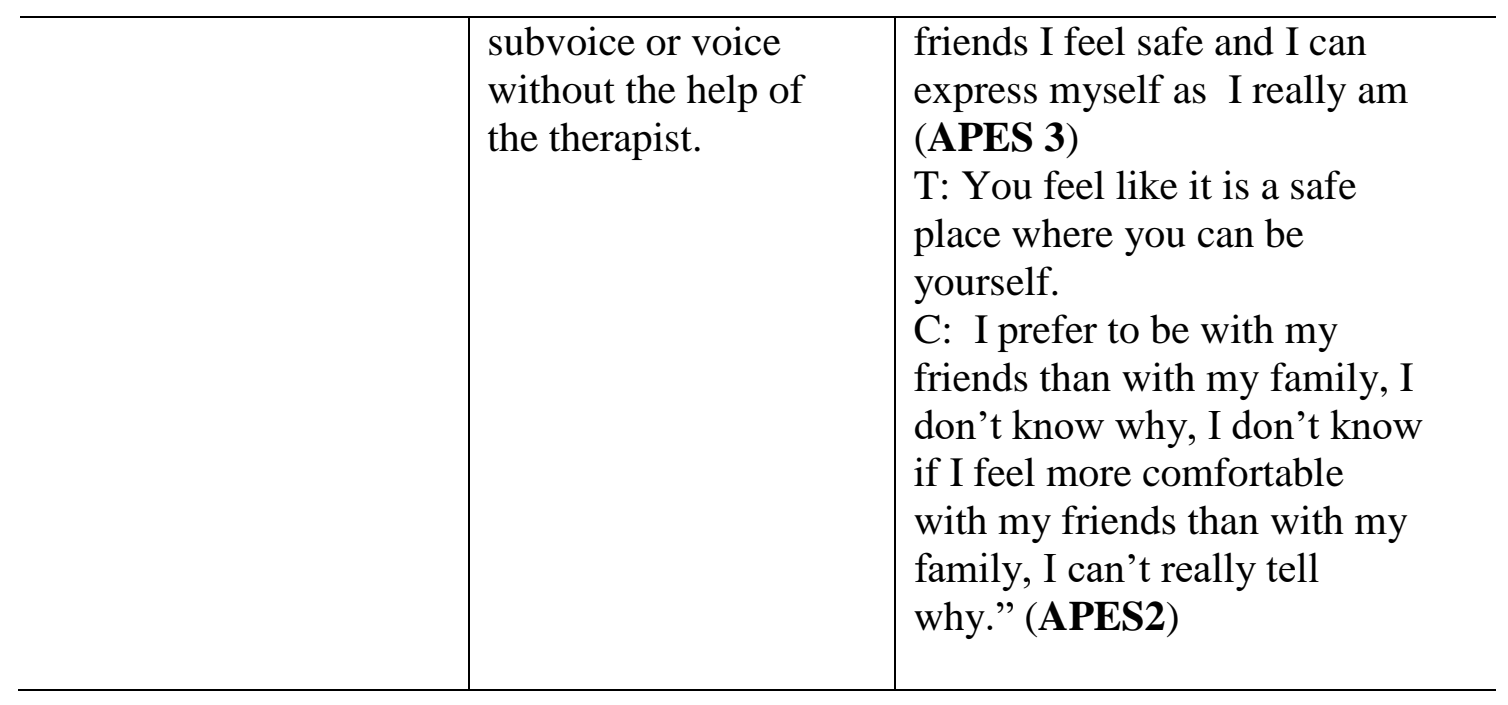


Table 2

Setbacks in Alice's assimilation process

\begin{tabular}{cccc}
\hline & $\begin{array}{c}\text { Balance } \\
\text { Strategy }\end{array}$ & ZPD-T & $\begin{array}{c}\text { Spontaneous } \\
\text { Switch }\end{array}$ \\
\hline Session 1 & 2 & 1 & 2 \\
Session 4 & 4 & 0 & 0 \\
Session 8 & 2 & 1 & 1 \\
Session 12 & 1 & 0 & 7 \\
Session 16 & 3 & 0 & 2 \\
Total & 12 & 2 & 12 \\
\hline
\end{tabular}

Note: ZPD = zone of proximal development.

Table 3

Setbacks in Barbara's assimilation process

\begin{tabular}{ccccc}
\hline & $\begin{array}{c}\text { Balance } \\
\text { Strategy }\end{array}$ & ZPD-T & ZPD-C & $\begin{array}{c}\text { Spontaneous } \\
\text { switch }\end{array}$ \\
\hline Session 1 & 0 & 0 & 0 & 0 \\
Session 4 & 2 & 10 & 3 & 0 \\
Session 8 & 1 & 3 & 0 & 0 \\
Session 12 & 4 & 1 & 2 & 0 \\
Session 16 & 1 & 0 & 0 & 0 \\
Total & 8 & 14 & 5 & 0 \\
\hline
\end{tabular}

Note: ZPD = zone of proximal development. 
Figure 1. Alice assimilation process.

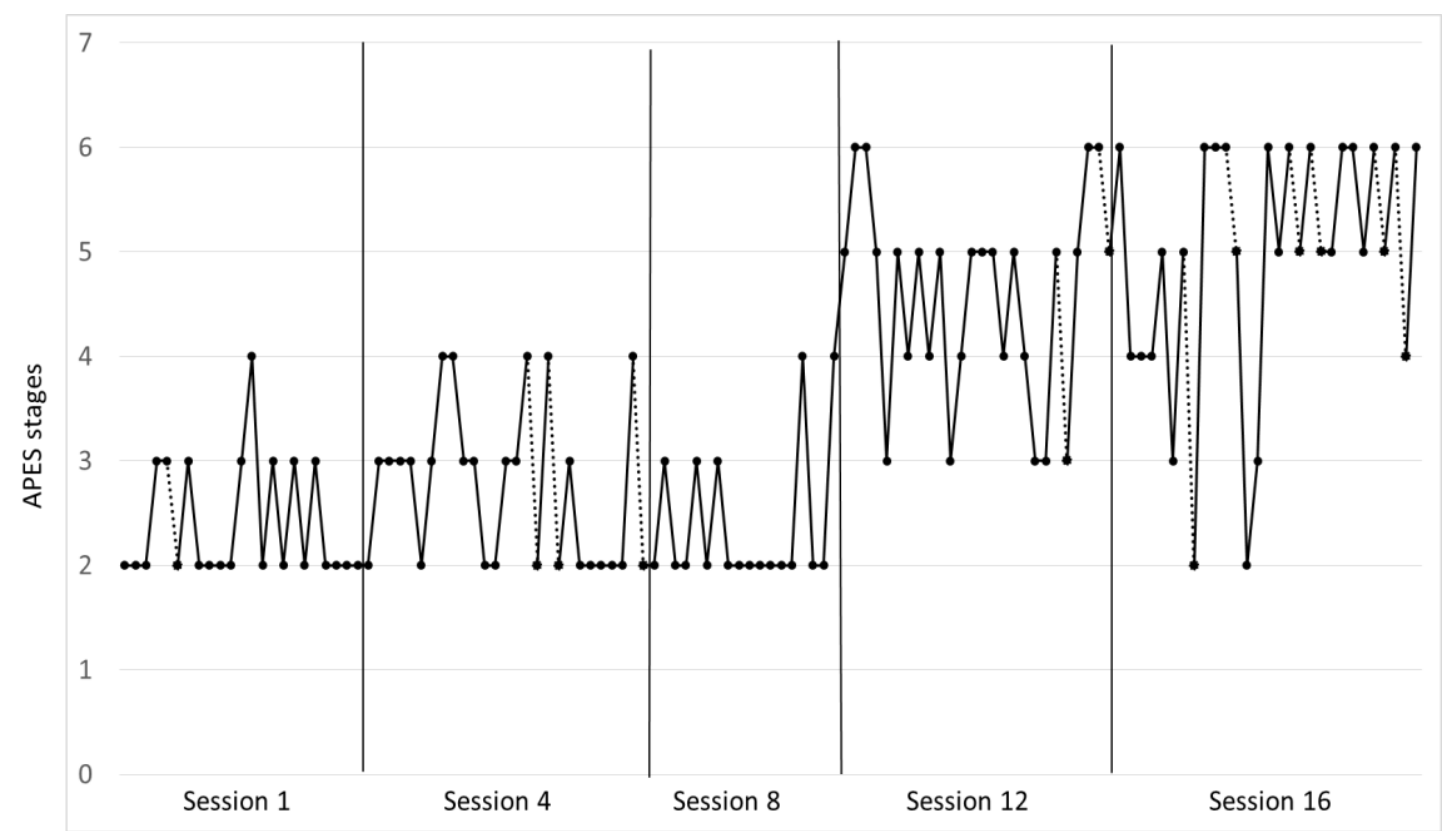

Note: Only retreats represented by solid lines were coded as setbacks. The lines with dots represent retreats that were not coded as setbacks since they involved a change of theme or they were not in adjacent passage.

Figure 2. Barbara assimilation process.

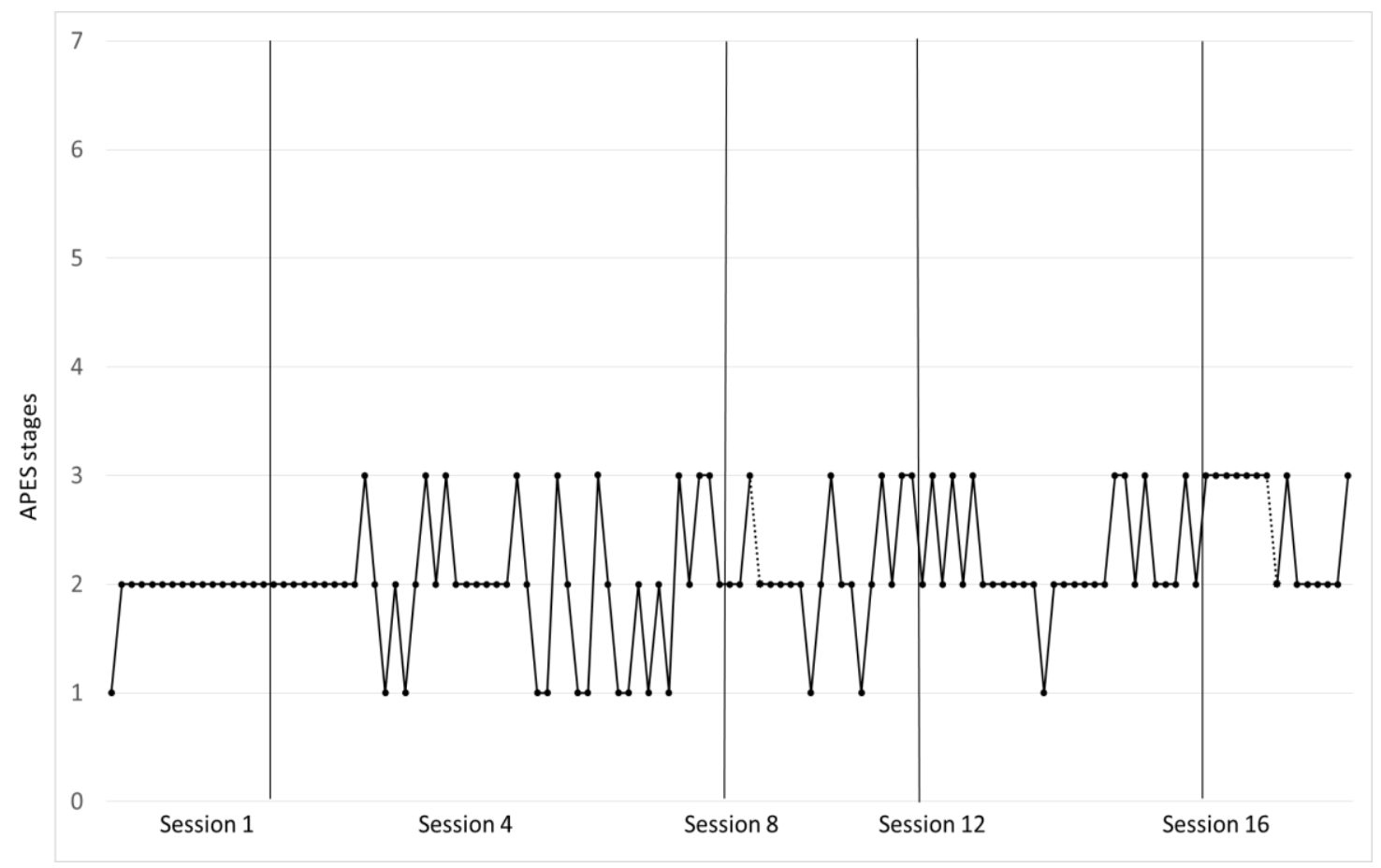

Note: Only retreats represented by solid lines were coded as setbacks. The lines with dots represent retreats that were not coded as setbacks since they involved a change of theme or they were not in the adjacent passage. 